\title{
Symptoms associated with reading from a smartphone in conditions of light and dark
}

\author{
Beatriz Antona $^{\mathrm{a}, *}$, Ana Rosa Barrio ${ }^{\mathrm{a}}$, Adriana Gascób, Ana Pinar ${ }^{\mathrm{b}}$, Mariano González-Pérez ${ }^{\mathrm{b}}$, María C. Puell ${ }^{\mathrm{a}}$ \\ ${ }^{a}$ Applied Vision Research Group, Faculty of Optics and Optometry, Complutense University of Madrid, 28037 Madrid, Spain \\ ${ }^{\mathrm{b}}$ Faculty of Optics and Optometry, Complutense University of Madrid, 28037 Madrid, Spain
}

\section{ART ICLE INFO}

Keywords:

Smartphone

Asthenopia symptom

Reading

Dark environment

\begin{abstract}
A B S T R A C T
Asthenopia symptoms were investigated in visually-normal subjects without computer-related vision symptoms after prolonged reading from: smartphone versus hardcopy under photopic conditions, and smartphone in conditions of ambient versus dark room illumination. After reading from the smartphone, total symptom scores and nine out of ten questionnaire symptoms were significantly worse than for the hardcopy ("blurred vision while viewing the text, "blurred distance vision after the task", "difficulty in refocusing from one distance to another", "irritated or burning eyes", "dry eyes", "eyestrain", "tired eyes", "sensitivity to bright lights" and "eye discomfort"). Mean total symptom scores and scores for "irritated or burning eyes" and "dry eyes" were significantly higher for the dark versus photopic conditions. In conclusion, prolonged smartphone reading could cause worse asthenopic symptoms than reading from a hardcopy under similar conditions. Symptoms could be even worse when reading from a smartphone in the dark.
\end{abstract}

\section{Introduction}

The use of computers and other digital screen devices for both professional and non-professional activities is practically universal in the developed world. In Forrester Research's largest annual survey of Americans' technology adoption, 73 percent of 37,000 respondents claimed that mobile phones were the electronic devices they most used (Schadler et al., 2013). Although the use of smartphones has recently increased among individuals of all age groups, young people continue to be the main users of mobile phones and $95 \%$ of these devices are smartphones. According to current estimates, at least one half of all users are connected to the Internet for a period exceeding half an hour per day and one user in ten connects to the Internet over more than $4 \mathrm{~h}$ a day (Ditrendia, 2015). Further, a recent survey reports that mobile device users spend more than $20 \mathrm{~h}$ a week emailing, text messaging and using social network services, indicating their heavy reliance on smartphones to connect and communicate with others (Lee et al., 2015).

Intensive use of the smartphone has been linked to musculoskeletal problems such as pain affecting the neck and shoulders, the severity of these symptoms increasing with the total time spent using a mobile device (Berolo et al., 2011; Kim, 2015; Lee et al., 2015). Although the use

\footnotetext{
* Corresponding author. Faculty of Optics and Optometry, Complutense University of Madrid, Av. Arcos de Jalón 118, 28037 Madrid, Spain.

Email address: bantona@ucm.es (B. Antona)
}

of electronic devices is also known to produce visual symptoms, relatively few studies have addressed the vision effects associated with the use of a smartphone. The relatively small screen and font size of these devices may necessitate close working distances, increasing visual demands (on both accommodation and vergence) over those needed for printed texts (Bababekova et al., 2011).

Digital displays emit light directly resulting in more stress to the human eye (Chen and Cranton, 2012). Young adults and children spend increasingly more time viewing electronic devices, and a rise in sleep deficiency in adolescents is today a major public health concern (Hysing et al., 2015). About $90 \%$ of young people sleep with their smartphones in or right next to their beds (Nick, 2012) and often wake up in the middle of the night to use their smartphone, during which they experience discomforting glare and strain to their eyes. Currently, most smartphones have a self adjusting brightness control, which adjusts the brightness of the display according to ambient lighting. However, this function is mainly designed for operation during the day and the display is usually too bright when working in a dark room since it is not possible to reach a sufficiently low level of illumination for comfortable reading without glare (Berolo et al., 2011). Besides, many users will not bother to adjust display brightness when using the smartphone in the dark.

Several studies have assessed symptoms produced in response to reading from a computer or electronic book (Chu et al., 2011; Mangen 
et al., 2013; Noyes and Garland, 2008; Hue et al., 2014; Lee et al., 2008, 2011; Siegenthaler et al., 2012; Gowrisankaran and Sheedy, 2015). Chu et al. when comparing a computer screen with paper reported significantly worse blurred near vision and mean total symptom scores following sustained computer use than those reported after hardcopy fixation under similar viewing conditions (Chu et al, 2011). In a comparison between the ebook or Ipad and hardcopy reading, Hue et al. observed no significant differences in total symptom scores, though scores indicating tired eyes and eye discomfort were significantly higher for the ebook than hardcopy. However, when comparing the Ipad with hardcopy, no significant differences in symptom scores were found (Hue et al., 2014). Eye symptoms are the most common health problems among users of digital screen devices (Blehm et al., 2005). These symptoms may include eyestrain, eye discomfort, dry eye, double vision, and blurred vision either at near or when looking into the distance after prolonged use (Rossignol et al., 1987), and coincide with the symptoms of the condition known as computer vision syndrome (CVS) (Gowrisankaran and Sheedy, 2015; Hayes et al., 2007). However, conditions when reading from a smartphone differ from those when reading from a computer (e.g., reading position, size screen, scrolling text) and we would expect differences in symptoms. This issue was addressed in this study.

As far as we know, no study has examined possible asthenopia symptoms associated with prolonged reading from a smartphone compared with hardcopy reading and neither have visual symptoms been assessed arising from prolonged reading from a smartphone in the dark.

Despite the recent rise in the use of smartphones in everyday life, possible visual symptoms associated with their prolonged use or use under non recommended conditions have not yet been explored in detail. The purpose of this study was to identify possible asthenopia symptoms associated with reading from a smartphone versus reading from a hardcopy. A further objective was to compare symptoms after reading from a smartphone in conditions of adequate ambient illumination versus in the dark. Reading speeds for the different sources and lighting conditions were also compared.

\section{Materials and methods}

This study was conducted at the Faculty of Optics and Optometry, Universidad Complutense de Madrid, Madrid, Spain. Measurements were obtained in 54 visually-normal subjects of mean age $23.7 \pm 2.6$ years (19-35 years). Subjects with under average visual acuity, gross accommodative dysfunction and disorders of binocular vision were excluded. The Computer Vision Symptom Scale (CVSS17), a new, validated questionnaire designed to assess computer-related visual and ocular symptoms associated with video display terminal usage (Gonzalez-Perez et al., 2014), was used to select subjects without symptoms related to habitual computer use. Inclusion criteria were a binocular distance and near corrected visual acuity of $0.1 \log$ MAR (ETDRS) or better, less than $0.1 \log$ MAR difference between the two eyes, no strabismus, no clinical diagnosis of dry eye, and no reported eye disease. Further inclusion criteria were at least $5.00 \mathrm{D}$ accommodative amplitude to rule out early presbyopia, near point convergence of $6.0 \mathrm{~cm}$ or less, near horizontal heterophoria (modified Thorington test) no greater than two esophoria or eight exophoria and a CVSS17 score lower than 36 points (see Table 1). The study protocol adhered to the tenets of the Declaration of Helsinki. All participants gave written informed consent prior to participation.

We performed two experiments, so the sample was divided randomly into two groups of subjects to avoid repeated sessions affecting symptom scores: Group $1(\mathrm{~N}=27)$ and Group $2(\mathrm{~N}=27)$ for Experiment 1 and 2 respectively. In both experiments, each participant was required to read two different texts at a viewing distance of $40 \mathrm{~cm}$ each
Table 1

Characteristics of the sample ( $\mathrm{N}=54 ; 29$ female).

\begin{tabular}{ll}
\hline Variable & Mean \pm SD \\
\hline Distance VA RE & $-0.04 \pm 0.08$ logMAR \\
Distance VA LE & $-0.04 \pm 0.10$ logMAR \\
Distance refraction RE & $-1.16 \pm 1.21 \mathrm{D}$ \\
Distance refraction LE & $-1.09 \pm 1.36 \mathrm{D}$ \\
Near point of convergence & $2.5 \pm 1.7 \mathrm{~cm}$ \\
Accommodative amplitude & $7.86 \pm 1.42 \mathrm{D}$ \\
Near horizontal heterophoria & $1.71 \pm 2.37 \Delta$ \\
CVSS17 & $26.06 \pm 4.33$ \\
\hline
\end{tabular}

VA: visual acuity. RE: Right eye. LE: Left eye. Distance refraction: Spherical equivalent $($ Sphere + Cylinder/2) of the habitual distance refraction. CVSS17: Computer Vision Symptom Scale.

for a continuous $20 \mathrm{~min}$ period in two different conditions. We maintained the same working distance and tilt angle for the reading tasks to ensure the same accommodative and convergence demands and be able to identify other possible sources of asthenopic symptoms. In Experiment 1 , we compared reading from a smartphone versus printed hardcopy, both in ambient photopic conditions. In Experiment 2, we compared reading from a smartphone under photopic illumination versus reading from the same smartphone in the dark.

In both experiments and for each subject, the order of the reading conditions was counterbalanced. Every subject was tested between 9 a.m. and 11 a.m. The two texts were randomly presented in each of the formats and had similar characteristics related to difficulty of comprehension and topic ("koalas" or "sharks"). We provided enough reading material for $20 \mathrm{~min}$ of reading without repetition. When using the smartphone, the subject scrolled through the text as required whereas when reading from paper, the subject turned the pages. To maximize compliance, participants were informed that after reading each text they would have to answer a few comprehension questions. This variable was not examined in the study. We also informed them that they would have to complete a short questionnaire describing their symptoms after reading.

In Experiment 1, the hardcopy text font and size was Arial 7 point and the same font was selected for the smartphones. For both formats, the angle subtended by the letters at $40 \mathrm{~cm}$ was approximately $13 \mathrm{~min}$ of arc (capital letter height $1.5 \mathrm{~mm}$ ). This height is within the recommended limits for letters displayed on a video display terminal, which range from 12 to 26 min of arc (mean 18) (Hennings and Nong, 1996). This letter size was selected so that reading would be somewhat demanding, although still in line with Grundy's recommendation that the visual acuity for a task should be at least twice that required to see the task (Grundy, 1981). The hardcopy text was presented in two columns $4.8 \mathrm{~cm}$ wide $\mathrm{x} 11.5$ tall printed horizontally on A4 paper. Inter-line distances were $<0.2 \mathrm{~cm}$.

In Experiments 1 and 2, to not restrict the study to a single brand, two smartphones (Iphone 4 and Motorola Moto-G) with similar characteristics (see Table 2) were randomly used when reading in the smartphone format. In Experiment 2, the subjects used the same smartphone for the two readings. On the smartphones, the texts were presented

Table 2

Technical characteristics of the smartphones used in the study.

\begin{tabular}{|c|c|c|c|}
\hline Smartphone & Display technology & Display size & $\begin{array}{l}\text { Display } \\
\text { resolution }\end{array}$ \\
\hline IPhone 4 & IPS Touchscreen LCD & $\begin{array}{l}4.8 \times 7.4 \mathrm{~cm} \\
3.5 \text { inches }\end{array}$ & $\begin{array}{l}640 \times 960 \\
\text { pixels }\end{array}$ \\
\hline Motorola & LCD TFT & $5.8 \times 9.8 \mathrm{~cm}$ & $720 \times 1280$ \\
\hline Moto G & $\begin{array}{l}\text { Touchscreen } \\
\text { Capacitive }\end{array}$ & 4.5 inches & pixels \\
\hline
\end{tabular}

IPS: in-plane switching. LCD: liquid crystal display. TFT: thin film transistor. 
within the WhatsApp application since letter size is standard across smartphones and this was the application most used by the participants to communicate with others. Inter-line distances were the same $(<0.2 \mathrm{~cm})$ than for the hardcopy. The column width of $4.8 \mathrm{~cm}$ for hardcopy text matched the width of the Whatsapp text in the smaller smartphone.

The photopic conditions of room lighting were artificial (fluorescent ceiling light). Target average luminance $\left(85 \mathrm{~cd} / \mathrm{m}^{2}\right.$ hardcopy, $255 \mathrm{~cd} /$ $\mathrm{m}^{2}$ smartphone) was checked using a MAVO-SPOT 2 USB luminance meter (Gossen Lighting Control). The auto brightness of the smartphone displays was disabled. The luminance level was higher for the smartphone than hardcopy format simulating normal conditions for these situations.

For reading in the dark in Experiment 2, we used a closed room where the only light source was the smartphone display. Before reading from the smartphone in the dark, subjects remained at least $5 \mathrm{~min}$ in the dark room to adapt to this illumination level.

For both experiments, the text was placed on a $50^{\circ}$ bookrest and subjects remained seated on a chair and read at a fixed distance of $40 \mathrm{~cm}$. Subjects wore their near vision refractive correction (spectacles or contact lenses) during the reading tasks. The two readings were separated by a rest period of at least $30 \mathrm{~min}$. Text order was also randomized. The number of words of the text read was recorded to calculate reading speed as the average number of words read per minute.

Immediately after each reading task, subjects filled in a printed questionnaire to assess visual strain from the task. This questionnaire was taken from Hayes et al. (2007) and has been also used by other authors for a similar purpose (Chu et al., 2011, 2014; Hue et al., 2014). The questionnaire consists of ten questions (listed in Tables 3 and 4) in which symptoms such as 'blurred vision", "dry eyes', or 'tired eyes' are graded on a 10-point Likert scale from 0 (not at all) to 10 (very severe), a score of five indicating a moderate response.

Table 3

Median symptom scores ( 0 none to 10 severe) awarded by participants after prolonged reading from a smartphone and hardcopy. Figures in parentheses are inter-quartile ranges Q1 to Q3. Significant score differences for smartphone versus hardcopy are indicated with an asterisk.

\begin{tabular}{|c|c|c|c|}
\hline \multicolumn{2}{|c|}{ Questions } & $\begin{array}{l}\text { Smartphone reading in } \\
\text { photopic conditions } \\
\mathrm{N}=27\end{array}$ & $\begin{array}{l}\text { Hardcopy } \\
\mathrm{N}=27\end{array}$ \\
\hline 1 & $\begin{array}{l}\text { Blurred vision while } \\
\text { viewing the text* }\end{array}$ & $2.0(1.0-4.8)$ & \multirow{2}{*}{$\begin{array}{l}1.0 \\
(0.0-3.0) \\
1.0 \\
(0.0-2.0)\end{array}$} \\
\hline 2 & $\begin{array}{l}\text { Blurred distance vision } \\
\text { after the task* }\end{array}$ & $2.0(0.0-4.0)$ & \\
\hline 3 & $\begin{array}{l}\text { Difficulty in refocusing } \\
\text { from one distance to } \\
\text { another* }\end{array}$ & $3.0(0.2-4.0)$ & $\begin{array}{l}1.0 \\
(0.0-3.0)\end{array}$ \\
\hline 4 & $\begin{array}{l}\text { Irritated or burning } \\
\text { eyes* }\end{array}$ & $2.0(0.0-5.0)$ & $\begin{array}{l}0.0 \\
(0.0-1.0)\end{array}$ \\
\hline 5 & Dry eyes * & $2.0(0.0-6.0)$ & $\begin{array}{l}1.0 \\
(0.0-2.0)\end{array}$ \\
\hline 6 & Eyestrain * & $3.0(1.2-5.8)$ & $\begin{array}{l}1.0 \\
(0.0-3.0)\end{array}$ \\
\hline 7 & Headache & $0.0(0.0-4.0)$ & $\begin{array}{l}0.0 \\
(0.0-0.0)\end{array}$ \\
\hline 8 & Tired eyes * & $4.0(2.0-5.0)$ & $\begin{array}{l}1.0 \\
(1.0-2.8)\end{array}$ \\
\hline 9 & $\begin{array}{l}\text { Sensitivity to bright } \\
\text { lights* }\end{array}$ & $2.0(0.0-6.5)$ & $\begin{array}{l}0.0 \\
(0.0-3.0)\end{array}$ \\
\hline 10 & Eye discomfort * & $3.0(0.0-4.0)$ & $\begin{array}{l}1.0 \\
(0.0-3.0)\end{array}$ \\
\hline \multicolumn{2}{|c|}{ Total symptom score * } & $25.0(16.3-42.0)$ & $\begin{array}{l}11.0 \\
(6.0-22.3)\end{array}$ \\
\hline
\end{tabular}

Table 4

Median symptom scores ( 0 none to 10 severe) awarded by participants after prolonged reading from a smartphone in photopic conditions or in the dark. Figures in parentheses are inter-quartile ranges Q1 to Q3. Significant score differences for photopic versus dark are indicated with an asterisk.

\begin{tabular}{|c|c|c|c|}
\hline \multicolumn{2}{|c|}{ Questions } & \multirow{2}{*}{$\begin{array}{l}\text { Smartphone reading } \\
\text { in photopic } \\
\text { conditions } \mathrm{N}=27 \\
2.0(1.0-3.0)\end{array}$} & \multirow{2}{*}{$\begin{array}{l}\text { Smartphone } \\
\text { reading in the } \\
\text { dark } \mathrm{N}=27 \\
1.0(0.0-4.0)\end{array}$} \\
\hline 1 & $\begin{array}{l}\text { Blurred vision while } \\
\text { viewing the text }\end{array}$ & & \\
\hline 2 & $\begin{array}{l}\text { Blurred distance } \\
\text { vision after the task }\end{array}$ & $2.0(1.0-3.8)$ & $3.0(1.0-5.0)$ \\
\hline 3 & $\begin{array}{l}\text { Difficulty in } \\
\text { refocusing from one } \\
\text { distance to another }\end{array}$ & $2.0(1.0-3.8)$ & $2.0(1.0-3.0)$ \\
\hline 4 & $\begin{array}{l}\text { Irritated or burning } \\
\text { eyes* }\end{array}$ & $0.0(0.0-3.0)$ & $2.0(0.0-4.8)$ \\
\hline 5 & Dry eyes* & $1.0(0.0-4.0)$ & $2.5(0.0-5.0)$ \\
\hline 6 & Eyestrain & $2.0(0.2-4.0)$ & $2.0(1.0-4.0)$ \\
\hline 7 & Headache & $0.0(0.0-1.8)$ & $0.0(0.0-1.8)$ \\
\hline 8 & Tired eyes & $2.0(0.2-4.0)$ & $2.0(1.0-5.0)$ \\
\hline 9 & $\begin{array}{l}\text { Sensitivity to bright } \\
\text { lights }\end{array}$ & $2.0(0.0-3.0)$ & $3.0(1.0-5.0)$ \\
\hline 10 & Eye discomfort & $2.0(0.0-5.7)$ & $3.0(1.0-5.0)$ \\
\hline \multicolumn{2}{|c|}{ Total symptom score * } & $16.0(8.3-35.7)$ & $\begin{array}{l}23.0 \\
(14.2-37.2)\end{array}$ \\
\hline
\end{tabular}

\subsection{Statistical analysis}

Data analysis was performed using Analyse-it for Microsoft Excel (Leeds, UK). The level of significance was set at $\mathrm{p} \leq 0.05$. Given that the Kolmogorov-Smirnov test indicated a non-normal distribution of scores for each of the 10 questions, we used the Wilcoxon paired sample test to compare symptoms and reading speed between the two formats (smartphone and hardcopy) and two illumination conditions (photopic vs dark). Asthenopia symptoms were compared according to the smartphone used by the Mann-Whitney $U$ test. We also used the Mann-Whitney $U$ test to check that there were no significant differences for each of the 10 symptoms between the two groups of subjects when reading from the smartphone in the photopic environment. Data outside 2.5 standard deviations from the mean were eliminated from the correlation analysis as outliers (1 subject).

\section{Results}

\subsection{Experiment 1: paper vs smartphone reading in photopic conditions}

Median symptom scores and interquartile ranges for reading from the smartphone and hardcopy are shown in Table 3. All symptom scores (except "headache") were greater after reading from the smartphone than hardcopy. Wilcoxon paired-sample tests between symptom scores for smartphone versus hardcopy indicated significant differences for "blurred vision while viewing the text" $(\mathrm{W}=141.5 ; \mathrm{p}=0.01)$, "blurred distance vision after the task" $(\mathrm{W}=126.5 ; \mathrm{p}=0.02)$, "difficulty in refocusing from one distance to another" ( $\mathrm{W}=111.0 ; \mathrm{p}=0.003)$, "irritated or burning eyes" $(\mathrm{W}=124.0 ; \mathrm{p}=0.003)$, "dry eyes" $(\mathrm{W}=130.0$; $\mathrm{p}=0.001)$, "eyestrain" $(\mathrm{W}=210.0 ; \mathrm{p}=0.0001)$, "tired eyes" ( $\mathrm{W}=174.0 ; \mathrm{p}=0.001)$, "sensitivity to bright lights" ( $\mathrm{W}=150.0$; $\mathrm{p}=0.02)$ and "eye discomfort" $(\mathrm{W}=194.0 ; \mathrm{p}=0.006)$. Median differences ranged from 1.0 to 3.0 points and 14 points of median difference for the total symptom score ( $\mathrm{W}=331.0 ; \mathrm{p}<0.0001$ ). No significant differences were detected for the symptom "headache".

According to the Mann-Whitney test, there were no significant differences in total symptom scores according to the text read (koalas vs sharks) (smartphone: $U=97 ; \mathrm{p}=0.5$ and hardcopy: $\mathrm{U}=135$; 
$p=0.3$ ) or order of reading (first vs second reading) $(U=99 ; p=0.6)$. Neither were significant differences recorded between the two different smartphones (I-phone vs Motorola) with regard to all the questionnaire symptoms and the total symptom score $(\mathrm{p}>0.05)$. Reading speeds differed significantly for the two formats such that higher speeds were observed when reading the printed text (192.4 words/ minute) than when reading from a smartphone (176.3 words/minute) $(\mathrm{W}=301 ; \mathrm{p}=0.007)$.

\subsection{Experiment 2: photopic vs dark smartphone reading}

Median symptom scores and interquartile ranges for reading from smartphone under two different ambient illumination conditions are shown in Table 4. Wilcoxon paired-sample tests between symptom scores for reading from smartphone in photopic versus dark conditions indicated significant median differences of 2.0 points for "irritated or burning eyes" ( $\mathrm{W}=31.0 ; \mathrm{p}=0.05), 1.5$ points for "dry eyes" ( $\mathrm{W}=21.5 ; \mathrm{p}=0.03$ ), and 7.0 points for the total symptom score $(\mathrm{W}=77.5 ; \mathrm{p}=0.04)$. No significant differences were detected between photopic and dark conditions in terms of scores awarded to other symptoms of the questionnaire.

According to the Mann-Whitney test, there were no significant differences in total symptom scores according to the text read (koalas vs sharks) (photopic condition: $\mathrm{U}=73 ; \mathrm{p}=0.2$ and dark: $\mathrm{U}=126$; $p=0.3$ ) or order of reading (first vs second reading) ( $U=97.5$; $\mathrm{p}=0.6)$. Smartphone reading speed did not differ significantly for the two illumination conditions ( $\mathrm{W}=169.5 ; \mathrm{p}=0.63$ ). Neither were significant differences recorded between the two different smartphones (I-phone vs Motorola) with regard to all the questionnaire symptoms and the total symptom score ( $\mathrm{p}>0.05$ ).

In addition, the Mann-Whitney $U$ test revealed no significant differences for each of the 10 symptoms, neither for the total symptom score between Group 1 and 2 when reading from the smartphone in photopic conditions $(\mathrm{p}>0.05)$.

\section{Discussion and conclusion}

Experiment 1 of this study was designed to compare eyestrain symptoms produced after reading for $20 \mathrm{~min}$ from a smartphone versus hardcopy. Median self-reported symptom scores were significantly higher by 1.0-3.0 points after the same reading task performed using a smartphone compared to hardcopy. The nine symptoms awarded higher scores after the smartphone task were (see Table 3): "blurred vision while viewing the text", "blurred distance vision after the task", "difficulty in refocusing from one distance to another", "irritated or burning eyes", "dry eyes", "eyestrain", "tired eyes", "sensitivity to bright lights" and "eye discomfort". Although symptoms after reading from a smartphone and hardcopy have not been previously compared, there are reports in the literature of studies addressing symptoms associated with the use of different digital books (Lee et al., 2008, 2011; Siegenthaler et al., 2012) or with viewing a computer screen or digital book versus hardcopy (Chu et al., 2011; Mangen et al., 2013; Noyes and Garland, 2008; Hue et al., 2014). This study supports previous findings of higher symptoms when reading from larger digital screens compared with hardcopy. A possible limitation of our experimental protocol was that being aware of the format they were using for the reading task, the participants' replies to the questionnaire items could have been influenced by a preference for one or other form of presentation.

The small screen and text size on a smartphone could determine a closer working distance and most likely a greater demand placed on ocular accommodation and vergence than when reading from paper
(Bababekova et al., 2011). Bababekova et al. measured both font size and viewing distance while individuals used a handheld electronic device. These authors concluded that for text messages, mean font size was 1.1 M-units (M) and the mean working distance was $36.2 \mathrm{~cm}$ (Bababekova et al., 2011). This viewing distance could experience some reduction after prolonged periods of reading (Long et al., 2015). For a text message on a smartphone, mean font size was comparable with newspaper print, which generally ranges from 0.8 to $1.2 \mathrm{M}$ (DeMarco and Massof, 1997).

Long et al. (2016) assessed eyestrain symptoms in 18 young adults performing a 60-min reading task on a smartphone. However, they only examined variables associated with the "internal symptom factor" (likely related to accommodative and/or binocular vision stress (Sheedy et al., 2003a)). Their results showed that eyestrain symptoms were greater and viewing distances closer at the end of the reading period. They found that subjects who reduced the viewing distance to a greater extent were more likely to report higher eyestrain symptom scores. For this reason, despite perhaps not reproducing the real preferences of subjects for reading, we maintained the same letter size and working distance for the reading tasks in the two formats to identify other possible factors able to explain the worse symptoms related to the smartphone. If we had used more real-life reading conditions (bigger letter size in hardcopy and/or shorter working distance for smartphone), we would expect an even higher level of symptoms when reading from the smartphones than hardcopy. This is because close viewing distances increase visual (accommodation and vergence) demands (Rosenfield, 2011; Tosha et al., 2009).

A possible factor able to explain the observed higher level of symptoms produced when reading from the smartphones than hardcopy could be the need to scroll the text while reading, causing a transient loss in sharpness. Simultaneously, this displacement of the text forces the subject to conduct successive visual searches along the text lines and accommodative adjustments. In effect, this could explain the higher scores awarded to items related to visual fatigue, eyestrain and accommodation symptoms after reading from a smartphone.

Further factors that could contribute to greater visual fatigue when using a smartphone could be screen reflections and the possibility of fingers occluding some of the text. Indeed, annoying reflections could prompt a change in head position and viewing direction. Hultgren and Knave assessed the effects of disturbances due to ceiling lighting reflections in an office landscape with computer display terminals and found that $53 \%$ of workers reported to have discomfort from reflections on screen (Hultgren and Knave, 1974). These factors could also explain the faster reading speeds we observed for the hardcopy compared to the smartphone reading task (192.4 vs 176.3 words/minute).

In our study, significantly higher scores for dry eye symptoms were obtained following the reading task from the smartphone. Dry eye should be kept in mind when working on display devices since this symptom is thought to be a major contributor to CVS, even after a brief period of time. Portello et al. (2013) and Uchino et al. (2008) reported a reduced blinking rate and higher percentage of incomplete blinks while subjects performed a task on a computer. These symptoms are likely also to affect smartphone users and could justify the greater symptoms of dry eye detected in our study compared to viewing a hardcopy. Chu et al. (2011) compared eye symptoms after 20 min of reading from a computer screen versus hardcopy. These authors mentioned that eye symptoms following prolonged computer use were significantly worse than after hardcopy fixation, specifically burred near vision and mean symptom score. Although non-significant, worse scores were also detected for dry eye. When comparing symptoms between the use of a computer screen and hardcopy, these same authors (Chu et al., 2014) found that blink rates were not reduced during computer operation. However, a greater percentage of incomplete blinks was detected during computer work, which could be associated with 
dry eye symptoms. This issue requires further investigation especially related to the use of handheld devices such as the smartphone.

Experiment 2 of this study was designed to compare eyestrain symptoms produced after reading for 20 min from a smartphone in photopic versus dark conditions. The total symptom score was significantly higher by 7 points in dark versus photopic conditions. The two symptoms awarded higher score after the smartphone reading task in the dark were (see Table 4): "irritated or burning eyes" and "dry eyes" (2 and 1.5 points respectively). This sensation is classified as an external symptom because symptoms are perceived on the front surface of the eye and can be induced by glare, small font, and flicker (Gowrisankaran et al., 2007).

Several studies have indicated the importance of balancing screen and background luminance. The Illuminating Engineering Society recommends that the luminance ratio between the task and near-surround area should not exceed three times in a working environment (Osterhaus, 1993). Large luminance ratios could reduce human visual comfort and decrease visibility as well (Cox et al., 1999; Elliott and Bullimore, 1993). Reading from a smartphone in a dark environment is notoriously above this ratio, especially if the brightness of the display is not reduced as in our study. Currently, most smartphones are provided with a so-called auto brightness function, which adjusts display brightness according to the environment. However, this function is mainly designed for operation in daytime and the display is too bright when the phone is used in a dark place (Ma et al., 2012). Nooree et al. (2014) found that ideal backlight luminance levels for constant viewing of a smartphone in a dark environment was $40 \mathrm{~cd} / \mathrm{m}^{2}$. Not all smartphones are capable of such a low level of backlight luminance and/or many users probably do not bother to adjust display brightness when using their smartphone in the dark. We used the same screen brightness for both the photopic and dark conditions so that, the main difference between the two tasks was the level of ambient illumination. Considering that when reading in the dark, the luminance ratio was far above that recommended, we can attribute the significant symptoms "irritated or burning eyes" and "dry eyes" to the discomforting glare produced by the display. Eyelid squint has been shown to provide benefits, decreasing retinal illumination under conditions of glare (Sheedy et al., 2003b, 2005). However, maintaining different levels of voluntary eyelid squint reduces the blink rate which is almost certainly related to the symptoms of dry eyes that are common among computer users. It has also been shown that symptom sensations and their perceived locations caused by a glare source are similar to those caused by dry eye (Sheedy et al., 2003c).

It is unlikely that ocular fatigue influenced the results of our study because symptom scores were not higher after the second reading task in comparison with the first. Thus, 20 min of continuous reading in the study conditions were sufficient to cause symptoms. Otherwise, we would expect more symptoms after the second reading. In addition, no differences were detected in symptoms according to the text read (koalas or sharks).

Reading speed was found not to depend on reading order (first vs second reading), nor the text read (koalas or sharks) or smartphone used. The two smartphones shared similar technical characteristics so this was expected. Yang et al. (2011) also reported no significant differences in reading speeds even using different technology smartphones.

Also as expected, there were no differences in visual symptom levels arising from the mobile devices used given their slight differences in display size and resolution. Yang et al (2011) also detected no significant differences in viewing discomfort between different smartphones.

The participants of this study were 54 visually-normal young subjects without computer vision symptoms. It could be interesting to redo the experiments in a sample of subjects with visual and/or ocular symptoms in their daily lives. Very probably, the worse symptoms re- lated to prolonged reading from a smartphone found in this study will be even more evident in symptomatic subjects.

In conclusion, our findings provide evidence to suggest that prolonged reading from a smartphone display could cause worse asthenopic symptoms than when reading from a hardcopy under similar conditions. These symptoms could be even worse when reading from a smartphone in the dark, especially if display brightness is high. We recommend restricting the prolonged use of smartphones to prevent ocular and visual symptoms.

\section{Conflict of interest}

All authors certify that they have NO affiliations with or involvement in any organization or entity with any financial interest (such as honoraria; educational grants; participation in speakers' bureaus; membership, employment, consultancies, stock ownership, or other equity interest; and expert testimony or patent-licensing arrangements), or non-financial interest (such as personal or professional relationships, affiliations, knowledge or beliefs) in the subject matter or materials discussed in this manuscript.

\section{Acknowledgments}

This work was supported by Financing program research groups UCM Complutense University of Madrid- Banco Santander 2014 (GR 3/ 14: 911302).

\section{References}

Schadler, T.; Yates, S.and Wang, N., 2013 Mobile Workforce Adoption Trends, in: https: //www.vmware.com/files/pdf/Forrester_2013_Mobile_Workforce_Adoption_Trends_ Feb2013.pdf, 2013Accessed 8 March 2016.

Bababekova, Y., Rosenfield, M., Hue, J., Huang, R., 2011. Font size and viewing distance of handheld smart phones. Optom. Vis. Sci. 88 (7), 795-797. https://doi.org/ 10.1097/OPX.0b013e3182198792.

Berolo, S., Wells, R., Amick, B., 2011. Musculoskeletal symptoms among mobile hand-held device users and their relationship to device use: a preliminary study in a Canadian university population. Appl. Ergon. 42 (2), 371-378. https://doi.org/10.1016/j. apergo.2010.08.010.

Blehm, C., Vishnu, S., Khattak, A., Mitra, S., Yee, R., 2005. Computer vision syndrome: a review. Surv. Ophthalmol. 50 (3), 253-262. https://doi.org/10.1016/j.survophthal. 2005.02.008

Chen, J., Cranton, W., 2012. Handbook of Visual Display Technology. Springer, London.

Chu, C., Rosenfield, M., Portello, J., Benzoni, J., Collier, J., 2011. A comparison of symptoms after viewing text on a computer screen and hardcopy. Ophthalmic Physiol. Opt 31 (1), 29-32.

Chu, C., Rosenfield, M., Portello, J., 2014. Blink Patterns: Reading from a Computer Screen versus Hard Copy. Optom Vis Sci 91, 297-302. https://doi.org/10.1097/OPX. 0000000000000157.

Cox, M., Norman, J., Norman, P., 1999. The effect of surround luminance on measurements of contrast sensitivity. Ophthal Physiol. Opt. 19, 401-414.

DeMarco, L.M., Massof, R.W., 1997. Distribution of print sizes in U.S. newspaper. J. Vis. Impair Blin 91, 9-13.

Elliott, D., Bullimore, M., 1993. Assessing the reliability discriminative ability, and validity of disability glare tests. Investig. Ophthalmol. Vis. Sci. 34, 108-119.

Gonzalez-Perez, M., Susi, R., Antona, B., Barrio, A., Gonzalez, E., 2014. The Computer-Vision Symptom Scale (CVSS17): development and initial validation. Investigative Ophthalmol. Vis. Sci. 55, 4504-4511. https://doi.org/10.1167/iovs.13-13818.

Gowrisankaran, S., Sheedy, J., 2015. Computer vision syndrome: a review. Work 52 (2), 303-314. https://doi.org/10.3233/WOR-15216.

Gowrisankaran, S., Sheedy, J., Hayes, J., 2007. Eyelid squint response to asthenopia-inducing conditions. Optom. Vis. Sci. 84 (7), 611-619. https://doi.org/10.1097/OPX. Ob013e3180dc99be.

Grundy, J., 1981. Visual efficiency in industry. Ophthalmic Opt. 15, 548-552.

Hayes, J., Sheedy, J., Stelmack, J., Heaney, C., 2007. Computer use, symptoms, and quality of life. Optom. Vis. Sci. 84, 739-745. https://doi.org/10.1097/OPX. 0b013e31812f7546.

Hennings, L., Nong, Y., 1996. Interaction of screen distances, screen letter heights and source document distances. Interact. Comput. 8, 311-322. https://doi.org/10.1016/ S0953-5438(97)83776-9.

Hue, J., Rosenfield, M., Saá, G., 2014. Reading from electronic devices versus hardcopy text. Work 47 (3), 303-307. https://doi.org/10.3233/WOR-131777.

Hultgren, G., Knave, B., 1974. Discomfort glare and disturbance from light reflections in an office landscape with CRT display terminals. Appl. Ergon. 5 (1), 2-8.

Hysing, M., Pallesen, S., Stormark, K., Jakobsen, R., Lundervold, A., Sivertsen, B., 2015 Sleep and use of electronic devices in adolescence: results from a large population-based study. BMJ Open 5, e006748. https://doi.org/10.1136/ bmjopen-2014-006748. 
Ditrendia, Informe Mobile en España y en el Mundo 2015, 2015. http://www.ditrendia. es/wp-content/uploads/2015/07/ Ditrendia-Informe-Mobile-en-Espa\%C3\%B1a-y-en-el-Mundo-2015.pdf, Accessed 8 March 2016.

Kim, M., 2015. Influence of neck pain on cervical movement in the sagittal plane during smartphone use. J. Phys. Ther. Sci. 27 (1), 15-17. https://doi.org/10.1589/jpts.27.15.

Lee, D., Shieh, K., Jeng, S., Shen, I., 2008. Effect of character size and lighting on legibility of electronic papers. Displays 29 (1), 10-17. https://doi.org/10.1016/j.displa.2007. 06.007.

Lee, D., Ko, Y., Shen, I., Chao, C., 2011. Effect of light source, ambient illumination, character size and interline spacing on visual performance and visual fatigue with electronic paper displays. Displays 32 (1), 1-7. https://doi.org/10.1016/j.displa.2010.09. 001.

Lee, S., Kang, H., Shin, G., 2015. Head flexion angle while using a smartphone. Ergonomics 58 (2), 220-226. https://doi.org/10.1080/00140139.2014.967311.

Long, J., Cheung, R., Duong, S., Paynter, R., Asper, L., 2015. Viewing distance and eyestrain symptoms with prolonged viewing of smartphones. In: Proceedings 19th Triennial Congress of the IEA, Melbourne.

Long, J., Cheung, R., Duong, S., Paynter, R., Asper, L., 2016. Viewing distance and eyestrain symptoms with prolonged viewing of smartphone. Clin. Exp. Optom. 100 (2), 133-137.

Ma, T., Lin, C., Hsu, S., Hu, C., Hou, T., 2012. Automatic brightness control of the handheld device display with low illumination. Comput. Sci. Automation Eng. 382-385.

Mangen, A., Walgermo, B., Bronnick, K., 2013. Reading linear texts on paper versus computer screen: effects on reading comprehension. Int. J. Educ. Res. 58, 61-68. https:// doi.org/10.1016/j.ijer.2012.12.002.

Nick, T., 2012. Using Your Smartphone before Bedtime Isn't a Good Idea, and Here's Why. Phone arena.

Nooree, N., Jang, J., Hyeon-jeong, S., 2014. Dynamics of backlight luminance for using smartphone in dark environment. In: Rogowitz, B., Pappas, T., Ridder, H. (Eds.), Proc.. of SPIE-IS\&T Electronic Imaging.

Noyes, J., Garland, K., 2008. Computer vs paper-based tasks: are they equivalent?. Ergonomics 51 (9), 1352-1375. https://doi.org/10.1080/00140130802170387.

Osterhaus, W., 1993. Office lighting: a review of 80 years of standards and recommendations. In: Proceedings of the 1993 IEEE Industry Application Society Annual Meeting. pp. 2-9.
Portello, J., Rosenfield, M., Chu, C., 2013. Blink rate, incomplete blinks and computer vision syndrome. Optom. Vis. Sci. 90 (5), 482. https://doi.org/10.1097/OPX. 0b013e31828f09a7.

Rosenfield, M., 2011. Computer vision syndrome: a review of ocular causes and potential treatments. Ophthalmic Physiol. Opt. 31, 502-515. https://doi.org/10.1111/j. 1475-1313.2011.00834.x.

Rossignol, A., Morse, E., Summers, V., Pagnotto, L., 1987. Video display terminal use and reported health symptoms among Massachusetts clerical workers. J. Occup. Med. official Publ. Industrial Med. Assoc. 29 (2), 112-118.

Sheedy, J., Hayes, J., Engle, J., 2003. Is all asthenopia the same?. Optom. Vis. Sci. 80 (11), 732-739.

Sheedy, J., Truong, S., Hayes, J., 2003. What are the visual benefits of eyelid squinting? Optom. Vis. Sci. 80, 740-744.

Sheedy, J., Hayes, J., Engle, J., 2003. Is all asthenopia the same?. Optom. Vis. Sci. 80 , 732-739.

Sheedy, J., Smith, R., Hayes, J., 2005. Visual effects of the luminance surrounding a computer display. Ergonomics 48 (9), 1114-1128. https://doi.org/10.1080/ 00140130500208414

Siegenthaler, E., Bochud, Y., Bergamin, P., Wurtz, P., 2012. Reading on LCD vs e-Ink displays: effects on fatigue and visual strain. Ophthalmic Physiol. Opt. 32 (5), 367-374. https://doi.org/10.1111/j.1475-1313.2012.00928.x.

Yang, S., Tai, Y.,Hayes, J. R. and Sheedy, J., Superior Smartphone display quality enhances viewing performance and comfort, 2011. Faculty Scholarship (COO). Paper 17 Pacific University http://commons.pacificu.edu/coofac/17Accessed 9 March 2016.

Tosha, C., Borsting, E., Ridder III, W., 2009. Accommodation response and visual discomfort. Ophthalmic Physiol. Opt. 29, 625-633. https://doi.org/10.1111/j.1475-1313. 2009.00687.x.

Uchino, M., Schaumberg, D., Dogru, M., Uchino, Y., Fukagawa, K., Shimmura, S., Satoh, T., Takebayashi, T., Tsubota, K., 2008. Prevalence of dry eye disease among Japanese visual display terminal users. Ophthalmology 115 (11), 1982-1988. https://doi.org/ 10.1016/j.ophtha.2008.06.022. 